\title{
Outbreaks of human infection caused by pyogenic streptococci of Lancefield groups $\mathbf{C}$ and $\mathbf{G}$
}

\author{
ANDROULLA EFSTRATIOU
}

Division of Hospital Infection, Central Public Health Laboratory, Colindale Avenue, London NW9 5 HT

\begin{abstract}
Summary. Within a collection of 749 strains of group C streptococci (Streptococcus equisimilis) and 2348 of group $\mathrm{G}$, isolated over a period of 6 years, there were clusters from 63 probable outbreaks of infection. These occurred in burns and maternity units, hospital wards, outpatient clinics, army camps and religious communities. Overall, it was possible to identify T-protein antigens in $88 \%$ of the group $\mathrm{C}$ strains and in $82 \%$ of group G. Serotyping by the identification of T-protein antigens was a useful method for the subdivision of these strains.
\end{abstract}

\section{Introduction}

The pyogenic streptococci of Lancefield groups $\mathrm{C}$ and $\mathrm{G}$ were recognised as causes of epizootics (Stafseth et al., 1937; Tillman et al., 1982) before they were considered as agents of infectious disease in man. There were very few descriptions before 1980 of cases of systemic disease caused by these organisms, but since then there has been an increasing awareness of the pathogenic potential of these streptococci, as reflected by the number of publications and notifications of serious infections reported to the Communicable Disease Surveillance Centre (CDSC) from laboratories in England and Wales (fig. 1).

These streptococci occur as commensals in the pharynx (Forrer and Ellner, 1979), on the skin (Gaunt and Seal, 1987), in the gut (Barnham, 1983) and in the female genital tract (Christensen et al., 1974). Serious diseases caused by these organisms include septicaemia (Finch and Aveline, 1984), endocarditis (Goldberg et al., 1985), septic arthritis (Gaunt and Seal, 1986), pneumonia (Stamm and Cobbs, 1980), meningitis (Devière et al., 1986), Cellulitis (Gaunt and Seal, 1987) and erysipelas (Hugo-Persson and Norlin, 1987). They have also been the presumptive cause of hospital and institutional outbreaks (Hill et al., 1969; McCue, 1982; Stryker et al., 1982; Cohen et al., 1987; Haynes et al., 1987; Teare et al., in press).

A serotyping scheme was developed by Efstratiou (1983) based on the detection of cell wall T-protein antigens and this has now been applied to more than 3000 'pyogenes-like' isolates of groups $\mathrm{C}$ and $\mathrm{G}$ from man.

Received 29 Nov. 1988; accepted 20 Jan 1989.

\section{Materials and methods}

\section{Strains}

A total of 3097 strains was examined. These included all streptococci isolated from both presumptive outbreaks and random incidents of infection. There were 2978 strains referred to this laboratory from hospitals and public health laboratories within the UK and 119 strains from five countries overseas. Amongst the overseas strains, 19 were from probable outbreaks of infection and 41 were sporadic non-related isolates. In addition, there were 59 pharyngeal cultures taken from two separate native indian communities in Canada; there was a high incidence of antibiotic resistance, notably to erythromycin, in these strains (personal communication, Dr L. E. Nicolle).

The Lancefield group antigen was identified by use of the "Streptex" grouping kit (Wellcome Diagnostics). A commercial identification kit (API 20 Strep, API Bio Merieux Ltd) was used to confirm the identification of 200 representative strains during the study. These were selected at random from non-related sources and also included representative strains from different outbreaks.

\section{T-protein typing scheme}

The T-protein antigens were identified by the agglutination of trypsinised suspensions of the streptococci with their homologous antisera. Strains to be tested were grown in Todd Hewitt Broth (Difco) supplemented with trypsin (Efstratiou, 1980). Slide agglutination tests were performed with the set of 20 specific polyclonal rabbit antisera (Efstratiou, 1983; Colman and Efstratiou, 1985).

The T-typing sera were prepared in rabbits by immunisation with either trypsinised whole cell vaccines or partially purified immunogens (Efstratiou, 1985). The agglutination test was performed as follows: the Tprotein suspensions were initially screened against five 


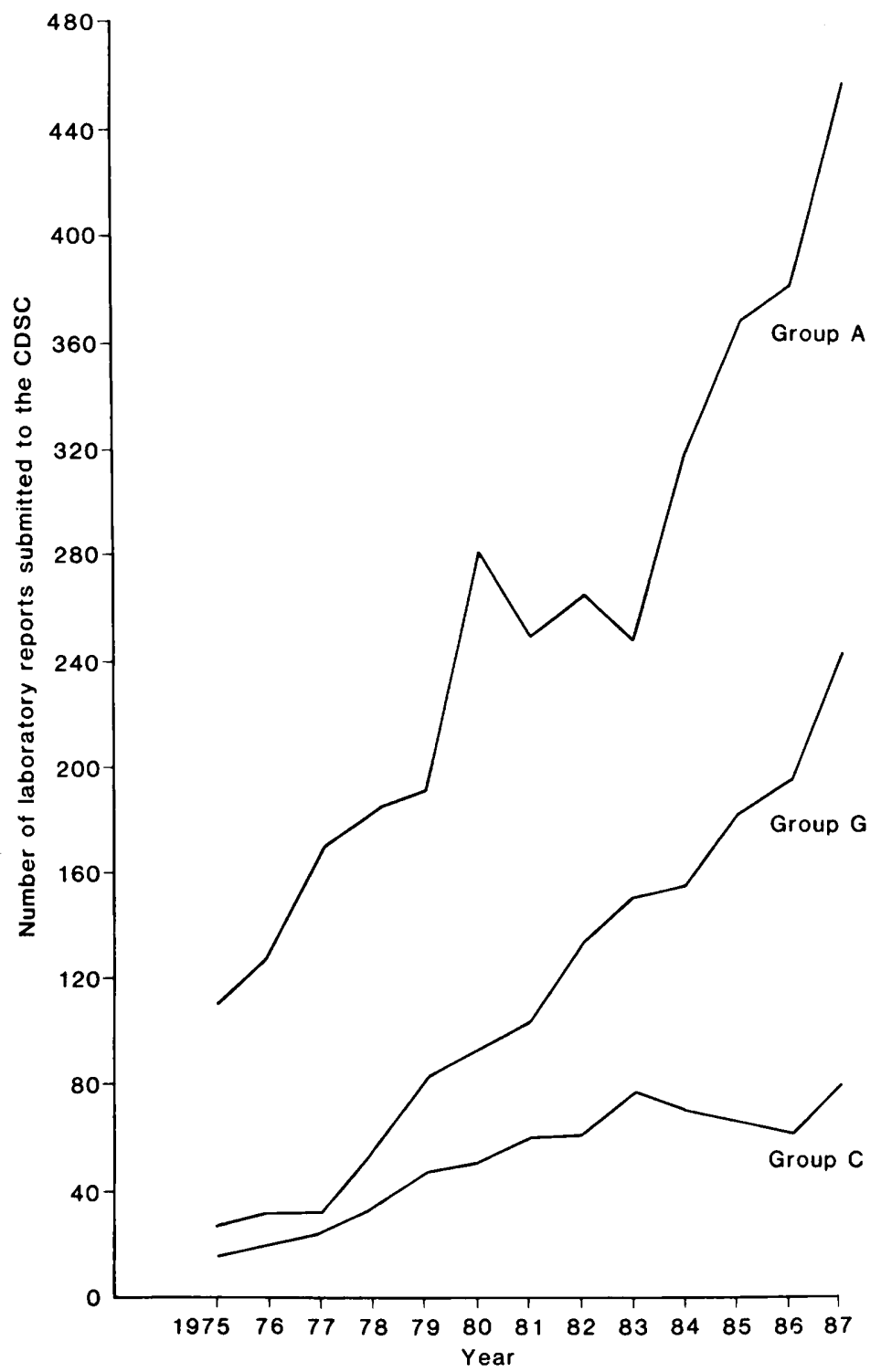

Fig. 1. Laboratory reports of groups A, C and G streptococci isolated from serious infections (1975-1987). Unpublished data of the Communicable Disease Surveillance Centre (CDSC).

pooled sera and if a reaction was obtained with any one of the pools the individual sera for that pool were examined. If agglutination did not occur the procedure was repeated with the set of T-typing sera prepared for group A streptococci.

\section{Results}

\section{Typability}

Of the 3097 isolates examined, 749 were Lancefield group C streptococci (Streptococcus equisimilis) and 2348 belonged to group G. In all, $88 \%$ of group
$\mathrm{C}$ and $82 \%$ of group $\mathrm{G}$ streptococci could be serotyped with the set of 20 antisera; group C streptococci were subdivided into $16 \mathrm{~T}$ serotypes and group $G$ streptococci into 19 (figs. 2 and 4). Cross-reactions between $T$ antigens of groups $C$ and $\mathrm{G}$ occurred with 339 strains. This was also the case with 89 strains of Lancefield groups $\mathrm{C}$ or $\mathrm{G}$ which carried the T-protein antigens, $2,4,28$ or $8 /$ 25/IMP 19 usually found in strains of group A (labelled " $a$ " in figs. 2, 3, 4 and 5). The T sera were specific for group C human isolates (S. equisimilis) and group $G$; the antigens were not detected in strains of other streptococcal groups. 


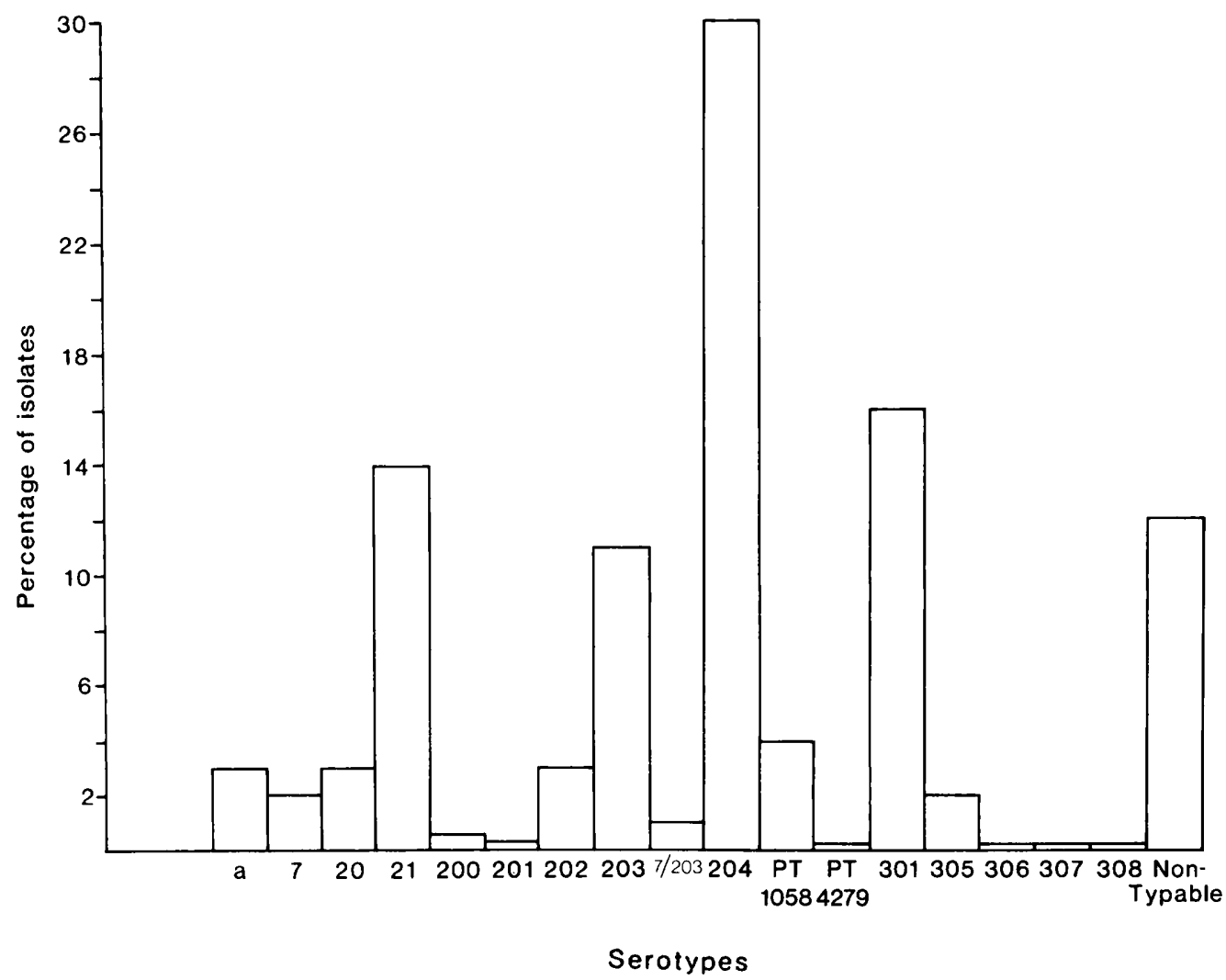

Fig. 2. Distribution of T-protein antigens in isolates of group C streptococci (S. equisimilis) (1982-1987). a: T-types 2, 4, 28 or 8/25/IMP19 complex.

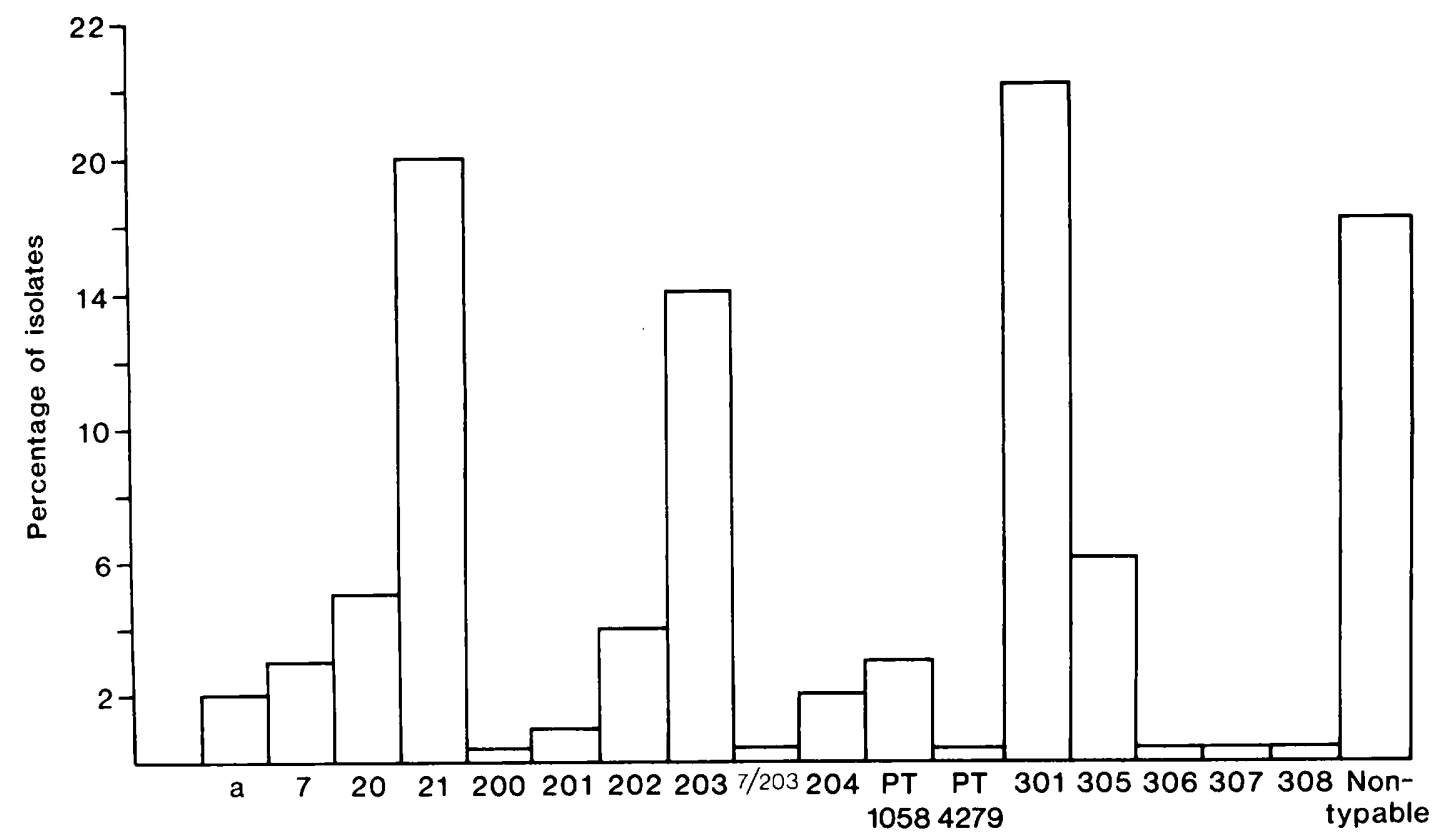

Serotypes

Fig. 3. Serotype distribution in epidemiologically independent isolates of $S$. equisimilis (1982-1987). 


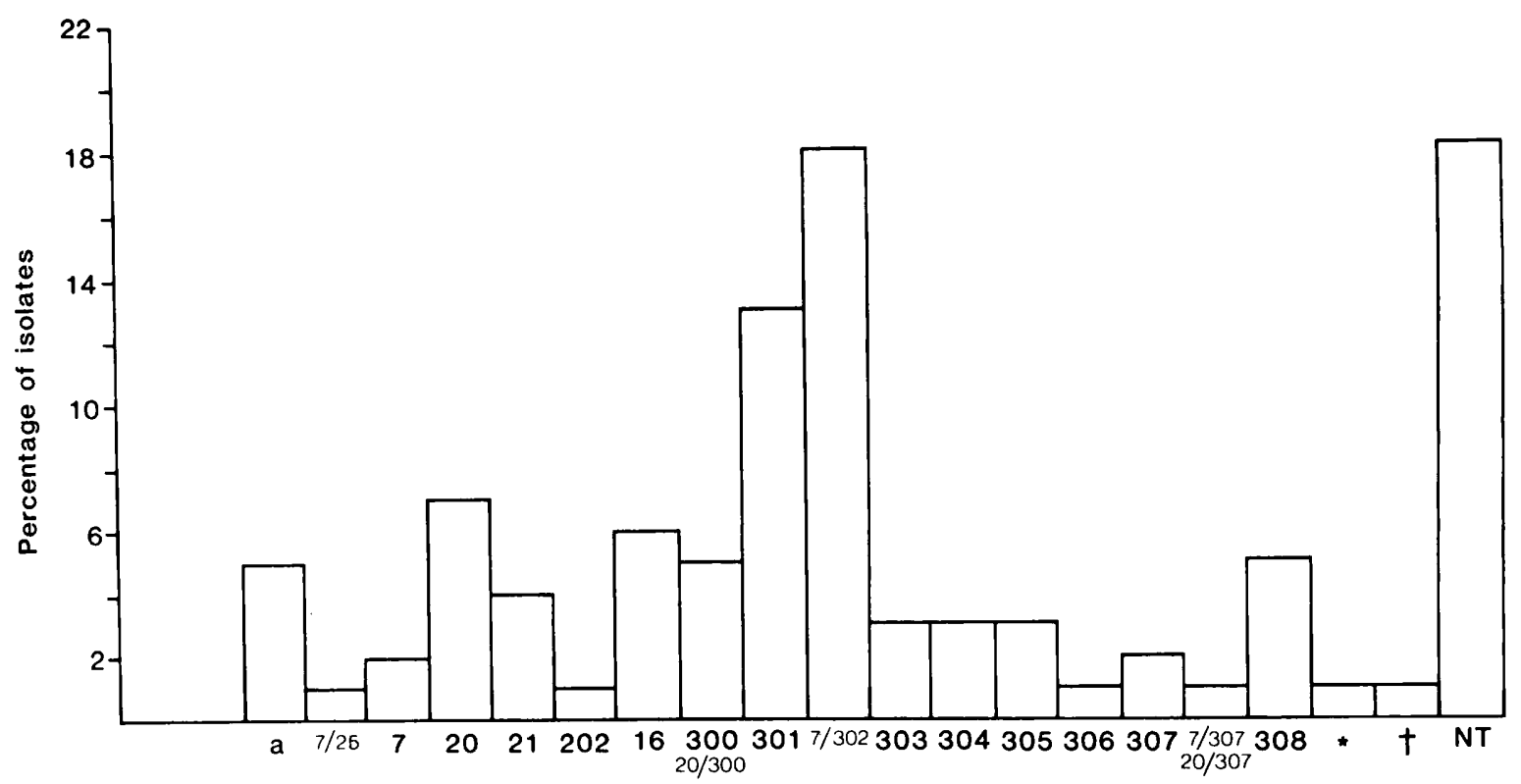

Serotypes

Fig. 4. Serological subdivision of group $\mathrm{G}$ streptococci by $\mathrm{T}$ typing over a 6-year period (1982-1987); * experimental T-type (PT 4860); $\uparrow$ complex T-pattern 7/302/305; NT = non-typable.

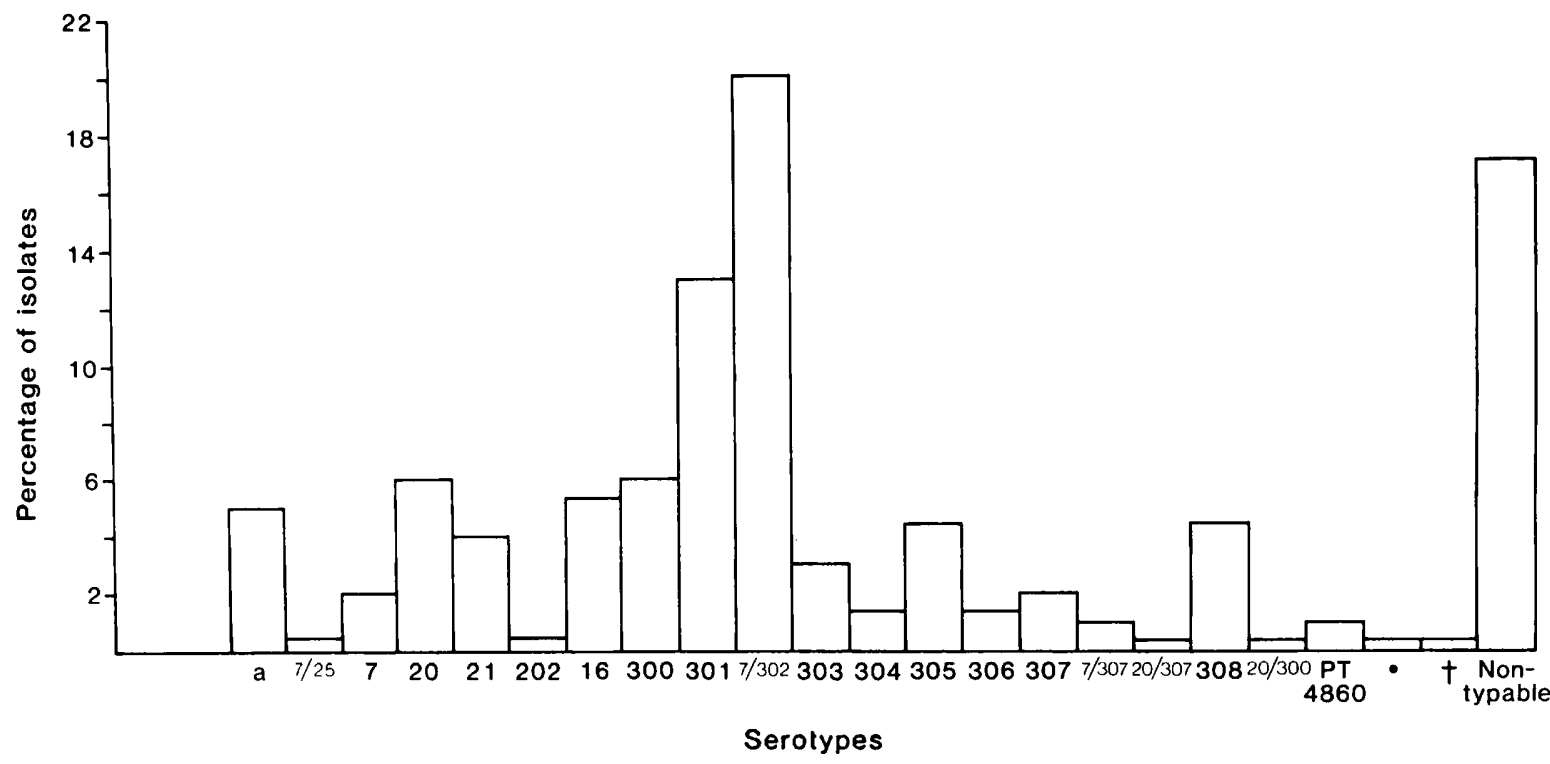

Fig. 5. $\mathrm{T}$ typing of non-related human isolates of group $\mathrm{G}$ streptococci by $\mathrm{T}$ typing; ${ }^{*}$ experimental $\mathrm{T}$ type (PT 4860); $\uparrow \mathrm{T}$-pattern $7 / 302 / 305$.

Distribution of serotypes among random isolates and relationship to disease

The serotype distribution for 482 strains of epidemiologically distinct group $C$ streptococci $(S$. equisimilis) is shown in table I; 137 strains carried
$T$ antigens first identified in strains of Lancefield group $\mathrm{G}$ and nine strains carried $\mathrm{T}$ antigens usually associated with Lancefield group A. Serotypes 21 and 301 together represented more than $40 \%$ of the total. The other serotypes produced distribution patterns within the range $0 \cdot 5-14 \%$ (fig. 2). The most 
common serotypes were 21,203 and 301 . The isolates examined were from various sites including the throat $(34 \%)$, raw areas of skin $(10 \%)$, leg ulcers $(9 \%)$, skin $(9 \%)$ and blood $(9 \%)$ (table I). Serotypes 21 and 203 predominated in patients with sore throat. Serotypes were evenly distributed among the 42 strains from blood cultures; 10 of these were from patients with endocarditis, four of whom had had previous mitral valve replacements. Four nontypable strains were isolated from patients with acute nephritis, one from a patient with post-natal renal failure in whom the streptococcus was isolated from a high vaginal swab and blood culture and one from a patient who developed nephritis 2 weeks after having had a sore throat from which a group $\mathrm{C}$ streptococcus had been isolated. Three cultures were from patients with meningitis. Overall, there did not appear to be any association of serotype with systemic disease.

Group G streptococci could be subdivided into more than $24 \mathrm{~T}$ types (table II). Cross-reactions occurred 282 times, $T$ antigens being identified in group $\mathrm{G}$ strains that are usually associated with Lancefield groups A (5\%) and C (13\%); these were types 2, 4, 28, IMP19 for group A, and types 7, 20, 21 and 202 for group C. Antigen 302 in group G strains was always complexed with antigen type 7 which was the most common single type and represented $20 \%$ of the isolates (fig. 5). Types 301 or $7 / 302$ were carried by $33 \%$ of the strains. The largest collections examined were from the throat $(17 \%)$, infected burns $(15 \%)$, leg ulcers $(16 \%)$, wounds $(11 \%)$, skin $(8 \%)$, female genital tract $(7 \%)$ and blood ( $7 \%$ ) (table II). Many were from systemic infections, including septicaemia, endocarditis and septic arthritis. Cultures were also obtained from cases of tonsillitis, otitis media, impetigo and cellulitis. The most common serotypes from these diseases were $7 / 302,301,300,16$ and 20 . Depending on the source, $74-100 \%$ of all isolates could be typed successfully.

Group $G$ streptococci were isolated from 130 severe infections such as septicaemia (85), endocarditis (25), meningitis (1) and septic arthritis (19). The most common serotype isolated from joint fluid or blood of patients with arthritis was type 20; septic arthritis in several patients was preceded by phlebitis. There was no association between any particular $T$ type and joint infection, but group $G$ strains isolated from joints and from other sites at the time of the arthritis were the same serotype. There was a wide distribution of serotypes amongst the isolates from blood cultures; types $7 / 302,300$, 301 and 20 were the most common. Of the 110 isolates, 85 were from patients with septicaemia associated with spontaneous peritonitis, catheter sepsis, infected leg ulcers, cellulitis, bronchial pneumonia, acute renal failure or endocarditis.

Neonatal and maternal infections accounted for $6 \%$ of the isolates, including 10 pairs of isolates from mothers and babies. Common serotypes were $7 / 302,20,21,301$ and 308. Serotype 308 was identified in strains isolated from a series of episiotomy wound infections in a maternity unit.

\section{Outbreaks of infection caused by Lancefield group C streptococci}

Outbreaks caused by these streptococci were not common; only 10 were reported during the 6 year study period including pharyngitis, skin sepsis and puerperal sepsis (table III). A single serotype was isolated from each of five institutional outbreaks of sore throat, including episodes of tonsillitis at two schools from which T-types PT 1058 or 21 were isolated, and an outbreak of pharyngitis in a military camp in which the T-serotype 4 was recovered from five throat swabs. Strains for serotyping were also received from an outbreak of pharyngitis which was followed by nephritis amongst schoolchildren in Romania (Mihalcu et al., 1982). The four sets of cultures carried the Ttype 204 antigen.

Four possible outbreaks of skin sepsis were studied (table III). In hospital B, four patients in a general medical ward developed skin lesions infected with group C streptococci, serotype PT1058. In the geriatric ward of hospital $\mathrm{C}$, three patients had skin sores infected with serotype 305 . Two outbreaks of infection in the burns unit of hospital D were caused by serotype 21 ; the first affected nine patients and the second, several weeks later, comprised four cases of sepsis, including one in which there was failure of skin graft. Throat cultures from the staff in attendance during the second incident yielded three isolates of serotype 21 . The fourth outbreak was relatively small; three patients in an old peoples' home had infected skin lesions and two developed cellulitis. Group C streptococci, serotype 204 were isolated from both cases of cellulitis.

There was one outbreak of puerperal sepsis in which 33 women were infected with serotype 204 (Teare et al., in press).

\section{Outbreaks of infection caused by group $G$ streptococci}

Strains were available for study from possible outbreaks of hospital-acquired infection that oc- 
Table I. Serotype distribution of non-related human isolates of S. equisimilis (Lancefield group C)

\begin{tabular}{|c|c|c|c|c|c|c|c|c|c|c|c|c|c|c|c|c|c|c|c|c|c|}
\hline \multirow[b]{2}{*}{ Source } & \multirow{2}{*}{$\begin{array}{c}\text { Total } \\
\text { number of } \\
\text { isolates }\end{array}$} & \multicolumn{20}{|c|}{ Number of isolates of $T$ serotypes } \\
\hline & & 7 & 20 & 21 & 200 & 201 & 202 & 203 & 204 & $\begin{array}{c}\text { PT } \\
1058\end{array}$ & $\begin{array}{c}\text { PT } \\
4279\end{array}$ & $\begin{array}{c}7 / \\
203\end{array}$ & 301 & 305 & 306 & 307 & 308 & 28 & $\underset{19}{\text { IMP }}$ & 4 & NT \\
\hline Aspirates & 6 & . & . & 1 & . & . & . & 2 & . & . & . & . & . & . & . & . & . & . & . & . & 3 \\
\hline Blood & 42 & 7 & 1 & 6 & . & . & 3 & 2 & . & . & . & 1 & 10 & 7 & . & . & . & . & . & . & 5 \\
\hline CSF & 3 & . & . & . & . & . &. & . & . & . & . & . & . & 3 & . & . & . & . & . & . & 0 \\
\hline Ear & 7 & . & 1 & 1 & . & . & . & 1 & . & . & . & . & 3 & . & . & . & . & . & 1 & . & 0 \\
\hline Eye & 2 & 1 & . & . & . & . & . & . & . & . & . & . & . & 1 & . & . & . & . & . & . & 0 \\
\hline HVS & 33 & 2 & 2 & 2 & . & 2 & 2 & 1 & 1 & . & . & . & 11 & 2 & . & . & . & 1 & 1 & . & 6 \\
\hline Nose & 3 & . &. & 1 & . &. & . & . & . & . & . & . & 1 &. & . & . & . & . & . & . & 1 \\
\hline Pus & 3 & . & 1 & . & . & . & . & . & . & . & . & . & 1 & . & . & . & . & . & . & . & 1 \\
\hline Raw areas of skin & 48 & 1 & 9 & 9 & . & . & 1 & 10 & . & 1 & . & . & . & 7 & . & . & - & - & . & 1 & 9 \\
\hline Sinus & 4 & . & . & 2 & . & . & . & . & . & . & . & . & 2 & . & . & . & . & . & . & . & 0 \\
\hline Skin & 44 & . & 1 & 8 & . & . & 3 & 4 & 2 & 1 & . & . & 13 & 3 & . & 2 & . & . & . & 1 & 6 \\
\hline Sputum & 4 & . & . & 3 & 1 & . & . & . & . & . & . & . & . & . & . & . & . & . & . & . & 0 \\
\hline Throat & 162 & 2 & 5 & 40 & 1 & 3 & 4 & 43 & 6 & 8 & 1 & . & 13 & 4 & . & . & . & . & 1 & 1 & 30 \\
\hline Ulcers & 45 & . & . & 2 & 1 & . & 1 & 4 & . & 8 & . & . & 20 & 1 & . & . & . & 1 & . & . & 7 \\
\hline Umbilicus & 4 & . & . & . & . & . & . & . & 1 & . & . & . & 3 & . & . & . & . & . & . & . & 0 \\
\hline Wounds & 33 & . & 2 & 6 & . & . & 3 & 3 & . & 2 & . & . & 8 & 1 & 1 & . & . & . & 1 & . & 6 \\
\hline Other & 39 & . & 2 & 6 & . & 1 & 3 & . & 1 & 2 & . & . & 11 & 1 & 1 & . & . & . & . & $\cdot$ & 4 \\
\hline Total & 482 & 13 & 24 & 87 & 3 & 6 & 20 & 70 & 11 & 22 & 1 & . & 96 & 30 & 2 & 2 & 7 & 2 & 4 & 3 & 78 \\
\hline
\end{tabular}

PT = Provisional type number, NT = Non-typable 
Table II. Serotype distribution of non-related human isolates of Lancefield group G streptococci

\begin{tabular}{|c|c|c|c|c|c|c|c|c|c|c|c|c|c|c|c|c|c|c|c|c|c|c|c|c|c|c|}
\hline \multirow[b]{2}{*}{ Source } & \multirow[b]{2}{*}{$\begin{array}{l}\text { Total number } \\
\text { of isolates }\end{array}$} & \multicolumn{25}{|c|}{ Number of isolates of $T$ serotypes } \\
\hline & & 16 & 300 & 301 & $\begin{array}{c}7 / \\
302\end{array}$ & 303 & 304 & 305 & 306 & 307 & $\begin{array}{c}7 / \\
307\end{array}$ & $\begin{array}{l}20 / \\
307\end{array}$ & 308 & 7 & $\begin{array}{l}7 / \\
25\end{array}$ & 20 & 21 & 4 & 28 & $\begin{array}{l}\text { IMP } \\
19\end{array}$ & 202 & $\begin{array}{l}20 / \\
300\end{array}$ & $\begin{array}{c}\text { PT } \\
4860\end{array}$ & 2 & * & NT \\
\hline Aspirates & 19 & 2 & 1 & 3 & 1 & $\cdot$ & $\cdot$ & $\cdot$ & $\cdot$ & $\cdot$ & . & $\cdot$ & · & $\cdot$ & $\cdot$ & 5 & 3 & $\cdot$ & $\cdot$ & 2 & 1 & $\cdot$ & $\cdot$ & $\cdot$ & $\cdot$ & 1 \\
\hline Blood & 110 & 11 & 9 & 13 & 20 & 1 & 2 & 5 & 2 & 2 & . & 1 & 32 & $\cdot$ & 6 & 32 & 3 & 1 & 3 & 2 & 1 & · & $\cdot$ & 18 & & \\
\hline CSF & 1 & . & . & . & 1 & . & $\cdot$ & $\cdot$ & $\cdot$ & . & $\cdot$ & $\cdot$ & . & $\cdot$ & $\cdot$ & · & $\cdot$ & $\cdot$ & $\cdot$ & $\cdot$ & $\cdot$ & . & $\cdot$ & . & $\cdot$ & 0 \\
\hline Ear & 28 & 1 & 2 & 3 & 4 & 1 & 1 & 1 & $\cdot$ & 1 & 1 & $\cdot$ & 1 & . & $\cdot$ & 2 & 2 & $\cdot$ & 1 & 2 & $\cdot$ & $\cdot$ & $\cdot$ & $\cdot$ & $\cdot$ & 5 \\
\hline Eye & 16 & 1 & $\cdot$ & 2 & 2 & 3 & $\cdot$ & $\cdot$ & $\cdot$ & . & $\cdot$ & $\cdot$ & $\cdot$ & 1 & $\cdot$ & 1 & 1 & $\cdot$ & 1 & $\cdot$ & $\cdot$ & $\cdot$ & $\cdot$ & $\cdot$ & $\cdot$ & 4 \\
\hline Faeces & 2 & . & . & . & 1 & . & . & . & . & . & . & . & . & 1 & . & . & . & . & . & . & . & . & . & . & . & 0 \\
\hline HVS & 118 & 1 & 4 & 10 & 44 & . & - & 4 & - & 4 & 2 & . & 5 & 1 & 1 & 11 & 9 & . & 2 & . & 2 & 1 & 2 & . & . & 15 \\
\hline Nose & 18 & 1 & 1 & 1 & 4 & 7 & . & 1 & - & . & . & . & 1 & - & . & . & - & . & . & - & . & - & . & . & 1 & 1 \\
\hline Pus & 10 & $\cdot$ & 1 & 4 & 3 & $\cdot$ & $\cdot$ & $\cdot$ & $\cdot$ & $\cdot$ & . & $\cdot$ & $\cdot$ & $\cdot$ & $\cdot$ & 2 & $\cdot$ & $\cdot$ & $\cdot$ & . & $\cdot$ & $\cdot$ & $\cdot$ & $\cdot$ & $\cdot$ & 0 \\
\hline Raw areas of skin & 225 & 12 & 28 & 38 & 42 & 4 & 3 & 16 & 7 & 7 & 2 & 1 & 14 & 1 & . & 4 & 9 & 1 & 1 & 4 & . & . & . & . & 1 & 30 \\
\hline Skin & 124 & 8 & 3 & 23 & 20 & 6 & 6 & 4 & 3 & $\cdot$ & . & $\cdot$ & 7 & 7 & . & 10 & 4 & 1 & 2 & . & . & . & . & 1 & . & 19 \\
\hline Sputum & 11 & 1 & . & 1 & 2 & . & . & 1 & . & . & . & . & 1 & . & . & . & . & . & . & . & . & . & . & . & . & 5 \\
\hline Throat & 254 & 22 & 25 & 42 & 31 & 1 & 3 & 7 & 7 & 6 & . & $\cdot$ & 16 & $\cdot$ & . & 22 & 8 & $\cdot$ & 6 & 4 & 2 & . & 4 & . & 1 & 47 \\
\hline Ulcers & 251 & 9 & 8 & 27 & 43 & 14 & 6 & 15 & · & 3 & 4 & $\cdot$ & 11 & 10 & $\cdot$ & 9 & 5 & 1 & 19 & 7 & $\cdot$ & . & . & . & $\cdot$ & 60 \\
\hline Umbilicus & 12 & 3 & . & 2 & 2 & 1 & $\cdot$ & $\cdot$ & 1 & · & $\cdot$ & $\cdot$ & $\cdot$ & 2 & $\cdot$ & $\cdot$ & 1 & $\cdot$ & $\cdot$ & $\cdot$ & $\cdot$ & . & $\cdot$ & $\cdot$ & $\cdot$ & 0 \\
\hline Urinary tract & 36 & 2 & 2 & 1 & 19 & 1 & . & 1 & . & 2 & . & $\cdot$ & 1 & - & . & 1 & 2 & $\cdot$ & 1 & $\cdot$ & . & - & . & - & $\cdot$ & 3 \\
\hline Wounds & 175 & 5 & 9 & 15 & 40 & 7 & 1 & 3 & 2 & 3 & 7 & $\cdot$ & 5 & 8 & 1 & 11 & 9 & 1 & 2 & 7 & 1 & . & 2 & . & $\cdot$ & 36 \\
\hline Other & 114 & 6 & 2 & 18 & 25 & 1 & 2 & 10 & $\cdot$ & 2 & $\cdot$ & $\cdot$ & 3 & 1 & 8 & 6 & 3 & 1 & 2 & 2 & $\cdot$ & $\cdot$ & 2 & 3 & 1 & 16 \\
\hline Total & 1524 & 85 & 95 & 203 & 304 & 47 & 24 & 68 & 22 & 30 & 16 & 2 & 68 & 34 & 10 & 90 & 59 & 7 & 40 & 29 & 9 & 3 & 11 & 4 & 4 & 260 \\
\hline
\end{tabular}

* New experimental T-type isolated from burns patients in 1987. 
Table III. Outbreaks of infection caused by Lancefield group C streptococci (S. equisimilis)

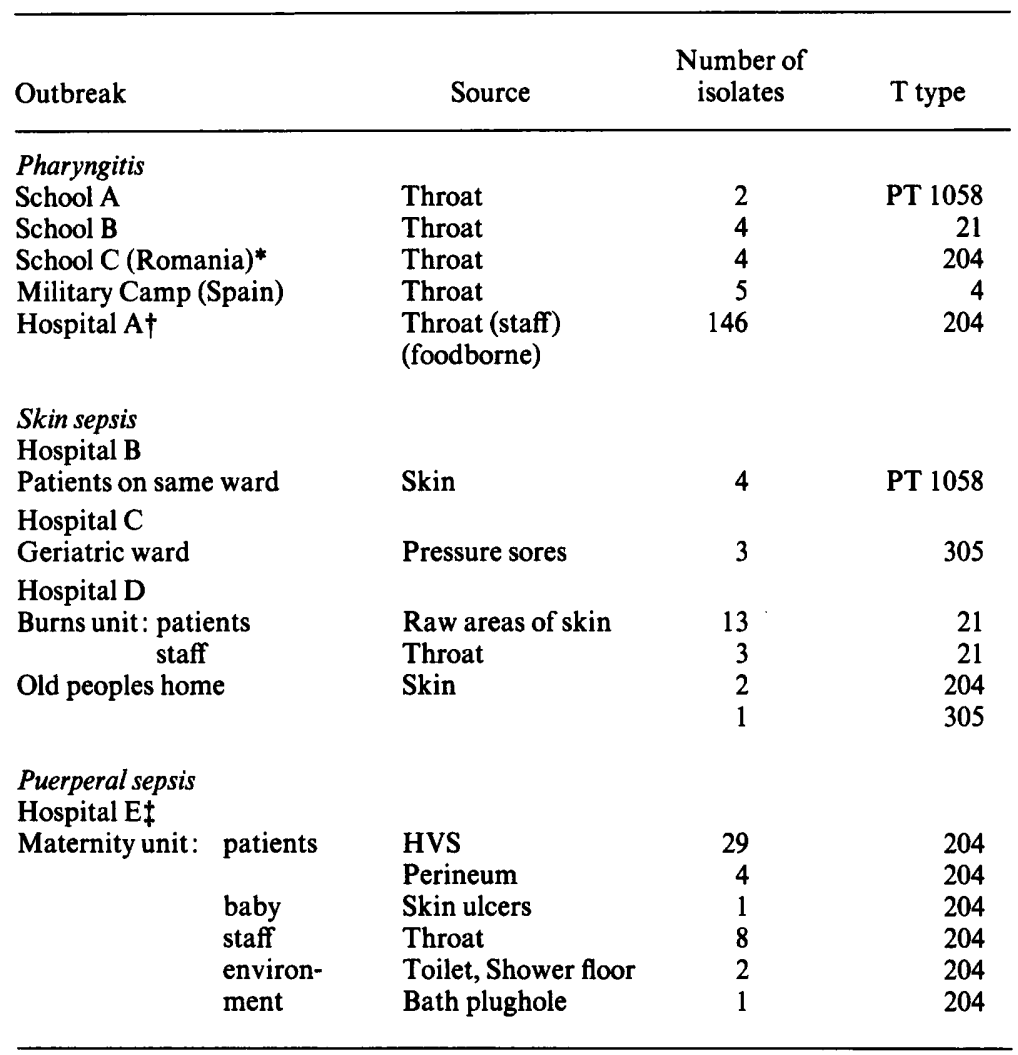

$\mathrm{PT}=$ Provisional type.

* Mihalcu et al., 1982; † Efstratiou et al., in press; $\ddagger$ Teare et al., in press.

curred in 41 institutions in the UK during the 6year study period. The main categories of infections were pharyngitis, skin sepsis and puerperal sepsis.

Infections in burns units. Group $\mathrm{G}$ streptococci are often isolated from burns and wounds. In one burns unit where group $\mathrm{G}$ streptococcal isolations were numerous, 759 patients were admitted during 1982-1985. The monthly isolations of group $A$ and group G streptococci are shown (fig. 6); $155(20 \%)$ patients were colonised with group $\mathrm{G}$ streptococci, $116(15 \%)$ with group $\mathrm{A}$, and $31(4 \%)$ with both. Certain serotypes predominated in different years (fig. 7); for example, serotype 301 was the most numerous type in 1982 and caused failure of skin grafts. This drew attention to the problem. Isolates with an unusual agglutination pattern were obtained from four patients at the same time; they were agglutinated by sera nos. 7, 302 and 305, and were the only representatives found with this pattern. Group $\mathrm{G}$ streptococci were also isolated from the environment and, occasionally, from nose and throat cultures of members of staff.
Smaller clusters of strains were examined from two other burns units. Eleven isolates from wound infections of patients in one unit comprised five different serotypes; four strains were type 305 , three type 20 , two type 307 , one type 16 and one $7 / 302$. In the third hospital 43 strains were isolated from infected patients in the burns and plastic surgery units over a 9-month period. Initially, crossinfection was suspected when large numbers of group $G$ streptococci were isolated from different patients simultaneously. Type 21 strains were also isolated from three patients, two members of staff in the burns ward, and five patients in the plastic surgery ward. Strains of type 308 were later found in three patients with burns and four patients in the plastic surgery unit.

Skin sepsis in hospital wards. The most numerous clusters of strains from hospitals were from cases of skin sepsis. The origin and serotype distribution of the 119 strains received are summarised in table IV. In all patients clinical signs of infection were present which had developed at sites of previous 
aroup A

$\square$ Group G

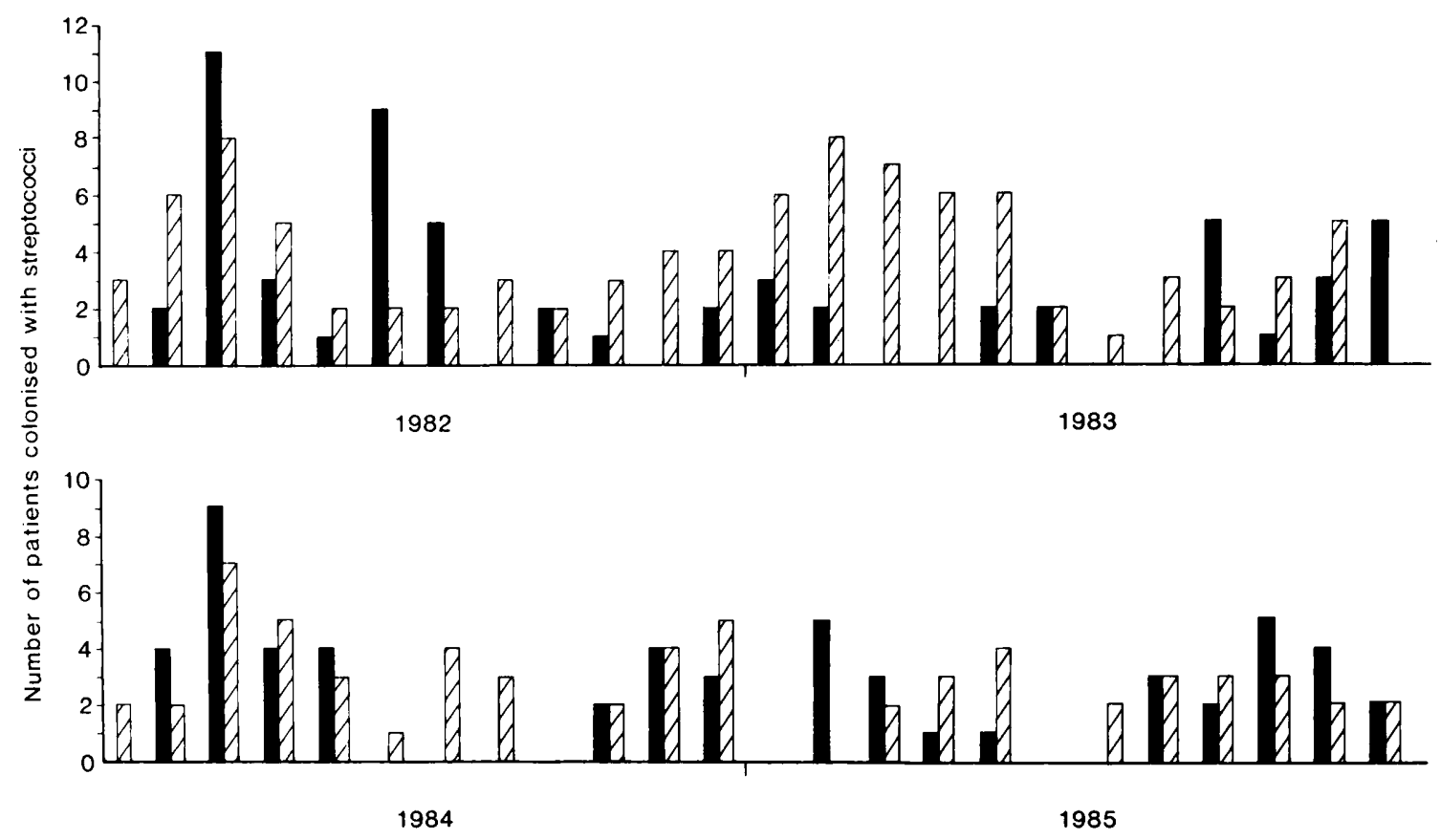

Fig. 6. Isolation of groups $A$ and $G$ streptococci in a London burns unit.

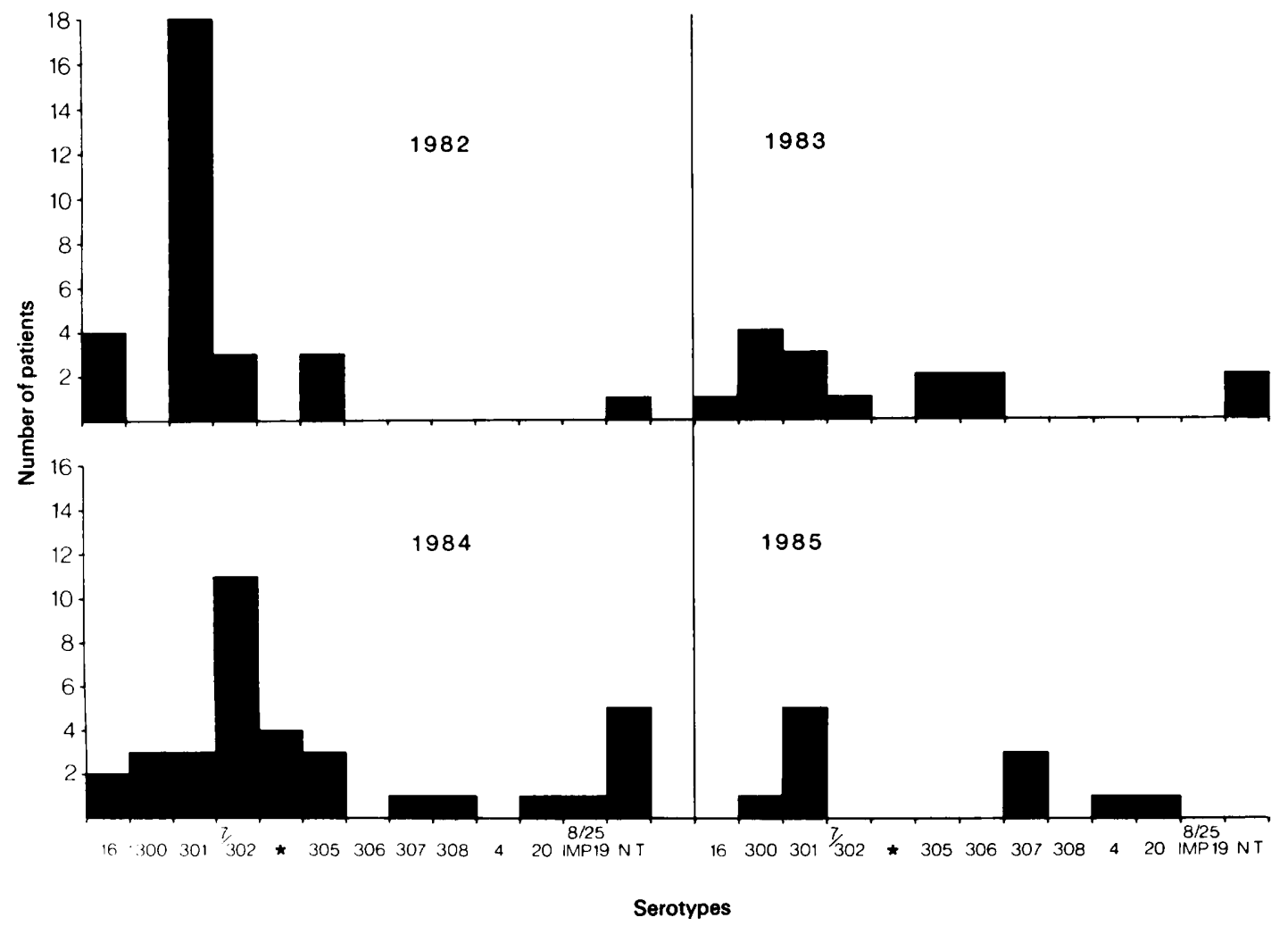

Fig. 7. Serotype distribution of group G streptococci in a London burns unit (1982-1985). * Complex T-pattern 7/302/305. 
Table IV. Outbreaks of skin sepsis in hospitals due to Lancefield group G streptococci

\begin{tabular}{clll}
\hline Hospital & Apparent outbreak in & Source of isolates & T-types (number of isolates) \\
\hline A & Plastic surgery unit & Skin grafts & T201(2), N.T.(2) \\
B & General ward & Sores, blisters & T301(3) \\
C & Ward & Sores, environment & T7/25(9) \\
D & Plastic surgery unit & Skin grafts & T301(4) \\
E & Ward & Wounds, leg ulcers & T303(1), N.T.(1) \\
E & Ward & Skin grafts & T20(2) \\
F & Plastic surgery unit & Skin grafts & T301(2), N.T.(2) \\
G & Ward & Leg ulcers & N.T.(2) \\
H & Ward & Skin sores & T301(5) \\
I & Geriatric intensive care & Wounds & T301(1), N.T.(3) \\
J & Ward & Skin sores & T7/302(1), N.T.(1) \\
K & Dermatology unit & Skin lesions & T308(6) \\
L & Ward & Leg ulcers & T305(2) \\
M & Psychogeriatric ward & Pressure sores & T16(1), T21(1), T301(1), N.T.(1) \\
N & Ward & Leg and elbow sores & T304(7) \\
O & Plastic surgery unit & Wounds & T7/302(4) \\
P & Ward & Skin grafts & T16(1), T7/302(1), N.T.(1) \\
Q & Ward & Leg ulcers & T305(4), T308(1) \\
R & Medical unit & Skin lesions & T7/302(3), T301(1), T305(1) \\
S & Wards 1-4 & Skin sores & T7(2), T20(1), T21(1), T7/302(6), \\
& & & T303(10), T7/307(1), N.T.(4) \\
T & Ulcer clinic & Leg ulcers & T7/302(6), N.T.(1) \\
U & Nursing home & Nose, skin & T303(11), T305(1) \\
& & & \\
\hline
\end{tabular}

damage to the skin. Types 303 (21 strains), 301 (14) and $7 / 302(20)$ were the commonest.

Outbreaks of infection in a London ulcer clinic. Thirty-seven strains of group $G$ streptococci were isolated from ambulatory patients attending a leg ulcer clinic. When the dressings were removed the infected wounds were left exposed prior to examination of the patients. During a 12-month period, 15 isolates of type 305 were recorded. This type was also isolated on three occasions from the floor of the clinic particularly beside the examination couch, and four times from the plastic aprons worn by the nursing staff. Type 7/302 strains were isolated from the skin of 12 patients attending the clinic at the same time and there were also sporadic isolations of other serotypes.

Outbreaks of infection in maternity units. In all, 104 strains were obtained from infections in 12 maternity units (table V). An outbreak of puerperal sepsis involving 12 patients occurred over 2 weeks

Table V. Group G streptococcal infections in maternity units

\begin{tabular}{|c|c|c|c|}
\hline Hospital & Source & Site of isolation & T-type (number of isolates) \\
\hline A & Mothers/Baby & Lochia/nose & $7 / 302(3)$ \\
\hline B & Mother/Baby & HVS/gastric aspirate, nose, rectum & $20(4)$ \\
\hline $\mathrm{C}$ & Babies & Cord, umbilicus & $301(2)$ \\
\hline $\mathrm{D}$ & Mothers & Perineum & $301(3), 7 / 302(5), 7 / 25(1), 28(1)$ \\
\hline $\mathbf{E}$ & Mothers/Staff(3) & Perineum/throat & $308(9), 7 / 302(2), * 308(1), *$ N.T.(2) \\
\hline $\mathbf{F}$ & Mothers & HVS, MSU, wounds & $7 / 302(12), 20(1), 21(1), 300(2)$ \\
\hline $\mathrm{G}$ & Mothers/Environment & Perineum/baths, toilets & $\dagger 7 / 302(16), 20(1), 21(1), 28(1), 301(1)$ \\
\hline $\mathrm{H}$ & Mothers/Staff(2) & HVS/throat & $7 / 302(2), * 300(1), * 308(1)$ \\
\hline I & Babies & Umbilicus, throat & $16(2)$ \\
\hline J & Mothers/Babies & HVS, wounds/eyes & $\pm 7 / 302(5), 300(1), 301(2), 305(1)$, N.T.(1) \\
\hline $\mathbf{K}$ & Mothers/Babies/Environment & HVS/umbilicus/shower & $7 / 302(1), 21(2)$ \\
\hline $\mathbf{L}$ & Mother/Baby/Staff(1) & HVS/throat/throat & $7 / 302(6), * 20(1)$ \\
\hline $\mathbf{M}$ & Mothers & Perineum, HVS & $7 / 300(1), 305(1)$ \\
\hline $\mathbf{N}$ & Mothers/Babies & HVS, MSU/urethra, cord & $7 / 302(5), 305(1), 306(1), 307(1), 16(1)$ \\
\hline $\mathrm{O}$ & Mothers & HVS & $20(3)$ \\
\hline
\end{tabular}

\footnotetext{
* Isolates from staff members; $\nmid$ isolates from the environment $; \ddagger 2$ isolates were from babies.
} 
at hospital F. Type 7/302 was isolated from all patients except one who had arrived in the unit after preventive measures, including the disinfection and thorough cleansing of bathrooms had been taken, and from whom type 21 was isolated. The outbreak ceased without the source being found. Type 7/302 strains were isolated from infections in hospitals D, G, H, K and L; this serotype was also isolated from environmental swabs (bath, bathwater, toilet seats, water closet and shower) taken in hospitals $G$ and $K$. None of nine strains isolated from a cluster of infected episiotomy wounds in hospital E, could be serotyped initially. Serum raised against one of these organisms (type 308) agglutinated all nine strains. Colonisation of babies with maternal strains was also observed in hospitals A, B and $\mathrm{K}$ (table V). Skin infections of babies who were in the neonatal unit at the same time occurred in hospitals $\mathrm{C}$ and $\mathrm{I}$.

Foodborne outbreaks of group $G$ streptococcal pharyngitis. Although such outbreaks are rare, strains were obtained from what were thought to be two such outbreaks -one in Florida, (Stryker $e t$ al., 1982), the other in an army camp in Israel (Cohen et al., 1987). All 10 strains available from the Florida cases were type 301 . None of the group $G$ streptococci isolated from soldiers with sore throats, kitchen workers or meat samples in the outbreak in Israel could be serotyped.

\section{Discussion}

The carriage rate of group $\mathrm{C}$ streptococci in normal individuals has been reported to be $3 \%$ by Hare (1940), but disease caused by these organisms is considered to be relatively uncommon (Stamm and Cobbs, 1980) although bacterial endocarditis, cellulitis, septicaemia, pneumonia, nephritis and meningitis have been recorded. The data provided in the present study confirm that these infections cannot be distinguished from those caused by group A streptococci ( $S$. pyogenes) on clinical criteria alone. There was no particular association of serotype with a specific disease.

Although outbreaks of infection due to group C streptococci are uncommon, nevertheless there were outbreaks of pharyngitis, skin sepsis and puerperal sepsis. The largest outbreak of sore throat studied involved 146 members of staff from one hospital (Efstratiou et al., in press) and was probably foodborne, a form of transmission that has not been recorded previously. Serotype 204, responsible for this outbreak, is uncommon in the community. Group C streptococci have not been described as a cause of outbreaks of puerperal sepsis but one such outbreak occurred during this study (Teare et al., in press) and strains of type 204 were isolated. The only other recorded outbreak caused by this type was in Romania where some throat infections were associated with subsequent cases of nephritis (Mihalcu et al., 1982). Phage-typing, DNA fingerprinting (Skjold et al., 1987) and the isolation of a common M-protein antigen (Efstratiou et al., in press) confirmed the similarities amongst these Romanian strains. M-protein antigens isolated from the UK outbreaks were identical but differed from the $M$-protein present on the Romanian strains (Efstratiou et al., in press). As with group A streptococci, representatives of different $M$ types may share a common $T$ antigen. Sporadic infections and outbreaks caused by group G streptococci are not entirely rare (Auckenthaler et al., 1983, Rolston, 1986). Group $G$ streptococci were subdivided into 18 different serotypes with an overall typability rate of $82 \%$.

Reports have noted the rarity of septic arthritis caused by group G streptococci (Armstrong et al., 1970; Lin et al., 1982). The recent recognition of group G streptococcal arthritis (Gaunt and Seal, 1986) may well be the result of improved identification procedures for streptococci now more generally available.

Group G streptococcal endocarditis has also been reported with increasing frequency (Bouza $e t$ al., 1978, Vartian et al., 1985, Smyth et al., 1988). Isolates of group $\mathrm{G}$ streptococci from the blood in this study represented $7 \%$ of random isolates. The clinical features of group $\mathrm{G}$ streptococcal bacteraemia in patients from one hospital have been described by Finch and Aveline (1984). There were five different $T$-protein antigens in their strains. There was no evidence of nosocomial spread. Acute glomerulonephritis after group $\mathrm{G}$ streptococcal infection is rare (Gnann et al., 1987), but some strains in this study were associated with glomerulonephritis, a finding that has also been reported in the West Indies following skin infections (Reid et al., 1985). Group G streptococci were also isolated from neonatal and maternal infections. Approximately $5 \%$ of women in labour harbour group G streptococci in their genital tract, so the occasional involvement of this organism in puerperal sepsis, endometritis and neonatal infection is not surprising (Filker and Monif, 1979; Dyson and Read, 1981).

There were 53 clusters of cases caused by group $G$ streptococci which represented probable outbreaks of infection. The diseases were similar to those caused by group A streptococci and included infections in burns units, detention centres, mater- 
nity units, hospital wards and outpatient clinics. The largest study on skin isolations of group $G$ streptococci was in a London burns unit. The typing scheme established that infections with different serotypes occurred in the unit at different times. In one outbreak, serotype 301 was associated with failure of skin grafts in several patients at the same time. Historically the predominant streptococcus in burns units has been $S$. pyogenes, reported by the Medical Research Council (1944) to be present in over $75 \%$ of burns, but now the incidence has been reduced to around $4 \%$ (Lawrence, 1985).

Pharyngitis comprises the most common outbreaks of group $\mathrm{G}$ infections. Streptococcal pharyngitis may be difficult to diagnose because asymptomatic throat carriage occurs in up to $23 \%$ of the normal population (Hill et al., 1969), and viruses are the more common cause of this infection. Apparent outbreaks of pharyngeal infection were examined in closed institutions such as detention centres, residential schools and army camps. In the American foodborne outbreak, the epidemiological data confirmed by the finding of the type 301 antigen in all strains suggested that the pharyngitis was caused by group $\mathrm{G}$ streptococci.

Outbreaks of puerperal fever caused by group $\mathrm{G}$ streptococci have been described only recently (Haynes et al., 1987). In all instances correlation of the typing results of isolates from the patients and from their bathrooms was consistent, and the failure to isolate other pathogens indicated that the puerperal fever was caused by group $\mathrm{G}$ streptococci. None of the babies born to infected mothers had invasive disease. These outbreaks of puerperal sepsis have drawn attention to the possible significance of group $\mathrm{G}$ in the genital tract of parturient women.

Overall, although the $\mathrm{T}$-protein antigens were very useful as epidemiological markers, they could not be related to virulence. The antiphagocytic molecule, the $\mathbf{M}$ protein has been identified in

\section{REFERENCES}

Armstrong D, Blevins A, Louria D B, Henkel J S, Moody M D, Sukany M 1970 Groups B, C and G streptococcal infections in a cancer hospital. Annals of the New York Academy of Science 174: 511-522.

Auckenthaler R, Hermans P E, Washington J A 1983 Group G streptococcal bacteremia: clinical study and review of the literature. Reviews of Infectious Diseases 5: 196-204.

Barnham M 1983 The gut as a source of the haemolytic streptococci causing infection in surgery of the intestinal and biliary tracts. Journal of Infection $6: 129-39$.

Bouza E, Meyer R D, Busch D F 1978 Group G streptococcal human isolates of Lancefield group $\mathrm{C}$ and group $\mathrm{G}$ streptococci (Efstratiou and Colman, in press) and a complementary typing scheme based on virulence factors may be useful because of its direct clinical relevance. The $\mathrm{T}$-typing in group $\mathrm{C}$ streptococci was successful in $88 \%$ of strains, in group $G$ strains $82 \%$. It is likely that these isolation rates could be increased by the preparation of additional T-typing sera.

The question of stability of serotypes, one form of reproducibility, could not be assessed accurately with a single serotyping scheme. The $T$ proteins are stable antigens and there was a high degree of reproducibility in epidemiologically related strains, e.g., the outbreaks in a skin ulcer clinic. In eight instances in the 26 burned patients from whom group $G$ strains were isolated over an extended period, sequential swabbing yielded more than one type. This can be explained by infection with a different serotype, but the possibility that some form of variation occurred in the $T$-protein antigen in the eight cases involved cannot be excluded. This could be clarified by the introduction of a complementary typing scheme based on the $\mathbf{M}$ protein antigens, as in group A streptococci; in current work 15 candidate M-types have been identified amongst group $\mathrm{C}$ and group $\mathrm{G}$ streptococci of human origin (Efstratiou and Colman, in press).

This study provides further evidence of the similarities in the pyogenic streptococci of Lancefield groups A, C and G, particularly in their cell wall protein antigens and their ability to cause sporadic systemic diseases and outbreaks of infections.

I am grateful to my colleagues in public health and hospital laboratories for providing the strains and clinical information, in particular Drs $\mathbf{M}$. Perinpanayagam and $\mathbf{M}$. Weinbren and Mr J. A. Clarke of Queen Mary's Hospital, Roehampton. I also thank Dr G. Colman and Professor B. I. Duerden for their advice and Mrs J. Sherling for typing the manuscript. endocarditis. American Journal of Clinical Pathology 70: 108-111.

Christensen K K, Christensen P, Flamholc L, Ripa T 1974 Frequencies of streptococci of groups A, B, C, D and G in urethra and cervix swab specimens from patients with suspected gonococcal infection. Acta Pathologica et Microbiologica Scandinavica B 82 : 470-474.

Cohen D, Ferne M, Rouach T, Bergner-Rabinowitz S 1987 Food-borne outbreak of group $\mathrm{G}$ streptococcal sore throat in an Israeli military base. Epidemiology and Infection 99: 249-255.

Colman G, Efstratiou A 1985 The investigation of outbreaks of infection caused by human strains of Lancefield group $\mathrm{C}$ or 
group G streptococci. In: Kimura Y et al. (eds) Recent advances in streptococci and streptococcal diseases. Reedbooks, Bracknell, Berks, pp 30-31.

Devière J, Bain H, Serruys E, Thys J P 1986 Septicaemia and meningitis caused by a group $\mathrm{G}$ streptococcus. Journal of Infection 13: 285-287.

Dyson A E, Read S E 1981 Group G streptococcal colonization and sepsis in neonates. Journal of Pediatrics 99: 944-947.

Efstratiou A 1980 Preparation of Streptococcus pyogenes suspensions for typing by the agglutination method. Medical Laboratory Sciences 37: 361-363.

Efstratiou A 1983 The serotyping of hospital strains of streptococci belonging to Lancefield group $\mathrm{C}$ and group $\mathrm{G}$. Journal of Hygiene 90: 71-80.

Efstratiou A 1985 The preparation of antisera to the T-proteins of Lancefield group C and Group G streptococci. Journal of Microbiological Methods 3: 141-146.

Efstratiou A, Colman G Lancefield group C and group G streptococci as human pathogens. In: Lutticken $\mathrm{R}$ (ed) Proceedings of the Xth Lancefield International Symposium on Streptococci and Streptococcal Diseases, Cologne, West Germany (in press).

Efstratiou A, Teare E L, McGhie D, Colman G The presence of $\mathrm{M}$ proteins in outbreak strains of Streptococcus equisimilis T-type 204. Journal of Infection (in press).

Filker R S, Monif G R 1979 Postpartum septicemia due to group-G streptococci. Obstetrics and Gynecology 53 Suppl 3: $28 \mathrm{~S}-30 \mathrm{~S}$.

Finch R G, Aveline A 1984 Group G streptococcal septicaemia : clinical observations and laboratory studies. Journal of Infection 9: 126-133.

Forrer O B, Ellner P D 1979 Distribution of hemolytic streptococci in respiratory specimens. Journal of Clinical Microbiology 10: 69-71.

Gaunt P N, Seal D V 1986 Group G streptococcal infection of joints and joint prostheses. Journal of Infection 13: 115-123.

Gaunt P N, Seal D V 1987 Group G streptococcal infections. Journal of Infection 15: 5-20.

Gnann J W, Gray B M, Griffin F M, Dismukes W E 1987 Acute glomerulonephritis following group $\mathrm{G}$ streptococcal infection. Journal of Infectious Diseases 156: 411-412.

Goldberg P, Shulman S T, Yogev R 1985 Group C streptococcal endocarditis. Paediatrics 75: 114-116.

Hare R 1940 Sources of haemolytic streptococcal infection of wounds in war and in civil life. Lancet 1 : 109-112.

Haynes J, Anderson A W, Spence W N 1987 An outbreak of puerperal fever caused by group $\mathrm{G}$ streptococci. Journal of Hospital Infection 9: 120-125.

Hill H R, Caldwell G G, Wilson E, Hager D, Zimmerman R A 1969 Epidemic of pharyngitis due to streptococci of Lancefield group G. Lancet 2: 371-374.
Hugo-Persson M, Norlin K 1987 Erysipelas and group G streptococci. Infection 15 : 184-187.

Lawrence J C 1985 The bacteriology of burns. Journal of Hospital Infection 6 Suppl B : 3-17.

Lin A N, Karasik A, Salit I E, Fam A G 1982 Group G streptococcal arthritis. Journal of Rheumatology 9: 424-427.

McCue J D 1982 Group G streptococcal pharyngitis: analysis of an outbreak at a college. Journal of the American Medical Association 248: 1333-1336.

Mihalcu F, Vereanu A, Andronescu C, Dumitriu S 1982 Group $\mathrm{C}$ streptococci, epidemiologic markers and implications in human pathology. Archives Roumaines de Pathologie Experimentale et de Microbiologie 41 : 123-131.

Medical Research Council 1944 Studies of burns and scalds. Medical Research Council, Special Report Series No. 249, H.M.S.O., London.

Reid H F M, Bassett D C J, Poon-King T, Zabriskie J B, Read S E 1985 Group G streptococci in healthy school-children and in patients with glomerulonephritis in Trinidad. Journal of Hygiene 94: 61-68.

Rolston K V I 1986 Group G streptococcal infections. Archives of Internal Medicine 146: 857-858.

Skjold S A, Quie P A, Fries L A, Barnham M, Cleary P P 1987 DNA fingerprinting of Streptococcus zooepidemicus (Lancefield group C) as an aid to epidemiological study. Journal of Infectious Diseases 155: 1145-1150.

Smyth E G, Pallett A P, Davidson R N 1988 Group G streptococcal endocarditis: two case reports, a review of the literature and recommendations for treatment. Journal of Infection 16: 169-176.

Stafseth H J, Thomson W W, Neu L 1937 Streptococcic infections in dogs. I. "Acid milk", arthritis, and postvaccination abscesses. Journal of the American Veterinary and Medical Association 90: 769-781.

Stamm A M, Cobbs C G 1980 Group C streptococcal pneumonia: report of a fatal case and review of the literature. Reviews of Infectious Diseases 2: 889-898.

Stryker W S, Fraser D W, Facklam R R 1982 Foodborne outbreak of group $\mathrm{G}$ streptococcal pharyngitis. American Journal of Epidemiology 116: 533-540.

Teare E L, Smithson R D, Efstratiou A, Devenish W R, Noah N D An outbreak of puerperal fever caused by group $C$ streptococci. Journal of Hospital Infection (in press).

Tillman P C, Dodson N D, Indiveri M 1982 Group G streptococcal epizootic in a closed cat colony. Journal of Clinical Microbiology 16: 1057-1060.

Vartian C, Lerner P I, Shlaes D M, Gopalakrishna K V 1985 Infections due to Lancefield group $\mathrm{C}$ streptococci. Medicine 64: 75-88. 